\title{
A Feasibility Study of Applying "Double-output Hypothesis" into Task-based Teaching Approach in Second Language Acquisition
}

\author{
Yongmei Jiang \\ Foreign Language School, Qingdao University of Science and Technology, Qingdao, China \\ Email: yongmeijiang716@126.com
}

\begin{abstract}
The "more input" and "less output" phenomenon is now very popular in college English teaching all over China. To increase the volume of the students' output and accordingly promote that of their input, this essay proposes "double-output hypothesis" and applies it into task-based teaching approach, i.e. combines writing and speaking. Writing provides the students enough language material, gets them prepared, and promotes their self-confidence for speaking tasks. The author proves this method feasible by experiments.
\end{abstract}

Index Terms - double-output, writing, speaking, task-based teaching approach

\section{INTRODUCTION}

At present, the "more input" and "less output" phenomenon is very popular in college English teaching all over China. It is commonly believed that reading and listening play a major role in language input and understanding, while speaking and writing have advantages in language output. The teaching emphasis is now widely put on cultivating and improving the language learners' communication ability and many foreign language teaching reforms are being undertaken with the focus on how to cultivate the students' communication ability. It is firmly believed that mastering speaking and writing skills is a sign of being able to communicate well. The language teachers and researchers have never stopped their research on how to enhance the output skills of speaking and writing.

\section{LITERATURE REVIEW}

Viewed from language acquisition itself and its social value, output, especially written output has a very important position. The theories in this area mainly include:

1. Krashen's (1985) comprehensible input hypothesis. It was introduced to China in the 1980s, and was once the focus of FLT and research. It holds that the language accepted by the learners must be understandable input.

2. As contrast to Krashen's comprehensible input hypothesis, Swain put forward the comprehensible output hypothesis. It began to be introduced to China in the 1990s. Swain (1995) argues that comprehensible input does not necessarily lead to learners' grammatical development, discourse, and sociolinguistic competence. Thus, she concludes that learners' production of modified output is another essential element in L2 acquisition.

Many researchers from this area believe that an isolated discussion of input and output will dissever their inner interdependent and interactive relationship. However, our present researches in China usually separate writing and reading, and carry out experiments or researches separately on writing and input/ output or on speaking and input/ output. There are almost no complete and accurate study of the relationship between input and output and their interaction.

\section{A NEW THEORY}

The writer here also believes that output plays an important role in language acquisition, but she also admits that presently there exists an obvious "more input" and "less output" phenomenon, and the two channels of writing and speaking have obvious disadvantages, which need to be improved urgently. In order to increase the students' language output and promote task-based teaching approach, and eventually improve the FLA performance, the writer put forward the "double-output hypothesis".

This hypothesis is based on the actual condition in the field of FLA presently in China, and it is a reorganization, integration and perfection of Swain's comprehensible language output. It mainly includes:

1. Input (including reading and listening or audio-visual) enough language materials, then have them processed by the brain and one part will be converted to acquisition material.

2. Free writing (which is focused on task and based on the input language material. Copy and dictation are not allowed and the time is limited). The acquired part of the input language material is required to be expressed in the form of writing with the help of the original language knowledge. Thinking in English is advised during the writing process, which is also a reorganization and consolidation of the input materials. 
3.When the students have discussions or do other oral tasks on class, they could be more confident, fluent, and accurate in grammar and vocabulary in expressing their opinions (which is focused on input material tasks carried out in writing, but they are not allowed to read what they have written), and the acquired part is further enhanced and internalized.

4. The combination of the two output channels is not simply from input to output, but a mutual interaction. Writing will promote oral expression, while oral expression will have a higher expectation for writing. Both of them will have a higher expectation for input content and its result, which will further promote listening and reading levels.

\section{A CASE STUDY}

This research, based on case study, is a preliminary exploration of the feasibility of applying "double-output hypothesis" to task-based teaching approach in FLA.

\section{A. Object}

The writer regards Class One of the two classes she teaches as the experiment group (EG), altogether 53 students; and Class Two as contrast group (CG), altogether 55 students. Both classes are from the same major of the same college, and all the students have passed the college national college entrance examination and have studied for half a year in our college. The experiment will last for eighteen weeks. Students from the two classes share other background conditions, for example, their speaking and writing levels are not high. They don't like communicating in English, and they are not good at listening but good at writing, and so on. For the contrast group, the writer continued to use the old teaching and managing method, but for the experiment group, she carried out the following experiment.

\section{B. Operation}

(1) Training: it was carried out on class and in several times.

1. train the students of learning strategies, including metacognition, cognition and social emotional strategy, and help them achieve efficient FL input and output by employing correct strategies. 2. Train the students of writing approaches, including free writing and thinking in English while writing. 3. Train the students of writing principles, helping the students to know what they are doing and why they are doing so and understand how the author expressed his ideas. The purpose is to promote reading and listening as effective input channel, provide rich language accumulation and get prepared for complex and oral output.

(2) Implementation 1. Give the students assignments on class and ask them to read, listen or see widely on a certain subject, and then undergo 10 minutes of free writing. The requirement is to think in English, not to copy or do by listening to some material, try to use language materials that have just been put in; the time to write is limited but the length of the writing is open, the longer the better. 2. At the next class, there will be group activities to carry out the tasks and do communicating exercises. Dividing the students into groups in three or six and each group will include students of different English levels, and there will be a leader. Every one is required to speak and tell the others his opinions, understanding and so on. They should evaluate each other's learning content and effect, report his own studying and gains and do group evaluation and mutual supervision. They can also introduce good learning methods and materials. With the sufficient previous input and writing output, they could communicate confidently and fluently, fully practicing their oral English. 3. Teacher supervision. The writer mainly get to know the students' learning conditions and give proper guide by joining in them on class discussion, using the time after school to correct their writings, and getting information from the group leaders.

(3) Test and result analysis. To see whether the learning approach is effective or not, there should be test both before and after the experiment. The writer did the oral tests respectively, but for the written tests, she used the final exams executed by the college during the end of the first term and the second term. Five of the test items are chosen and listed as follows. See table 1 and table 2:

TABLE 1

TEST BEFORE THE EXPERIMENT

\begin{tabular}{|c|c|c|c|c|c|} 
TEST BEFORE THE EXPERIMENT \\
\begin{tabular}{|c|c|c|c|c|c|}
\hline & oral & listening & reading & writing & total \\
\hline full & 10 & 35 & 30 & 15 & 110 \\
\hline Average of EG & 7.2 & 24.5 & 25.1 & 10.9 & 70.3 \\
\hline Average of CG & 7.1 & 23.1 & 25.7 & 11.1 & 71 \\
\hline
\end{tabular}
\end{tabular}

TABLE 2

TEST AFTER THE EXPERIMENT

TEST AFTER THE EXPERIMENT
\begin{tabular}{|c|c|c|c|c|c|}
\hline & oral & listening & reading & writing & total \\
\hline full & 10 & 35 & 30 & 15 & 110 \\
\hline Average of EG & 8.7 & 27.6 & 27.3 & 12 & 77.2 \\
\hline Average of CG & 7.2 & 26.4 & 26.1 & 10.3 & 72.1 \\
\hline
\end{tabular}

From the two tables above we can see that before the experiment there are not much difference between the two groups, actually they almost equal each other; but after five months' of experiment, the grades of the EG are all obviously higher than those of the $\mathrm{CG}$, with oral and writing especially better, 1.5 points higher than the average. 
Compared with the first test, the total grade of the EG is improved by 7.1 points, while that of the CG is only 1.8 points higher. Although this comparison is not very scientific, we can see this learning pattern is very helpful to the students' English learning, especially in oral and writing.

(4) Interview. After the test the writer interviewed the students from the EG and got some information about their viewpoints on this method and some feedback suggestions. Mainly the following four points: 1. It encouraged the students' participation confidence and activity and promoted the effectiveness of class learning and class atmosphere. 2. It is helpful in improving the students' English writing levels and they don't feel it difficult to write in English any more. 3. The fluency and accuracy of oral English are obviously improved. 4. It effectively improved the ability of listening and reading and so on.

(5) Limitations. This experiment has two apparent limitations: 1 . The number of participants. Because there is only one class participating, the experiment is limited in number and scope. 2. Time. The ability of language improvement concerns many complex elements. The result was got in one term and therefore its reliability will be challenged. Owing to the two points above, this experiment still has the space to be improved. If there were more teachers and classes participating the experiment and the time lasted longer, then the result would be more scientific and persuasive.

\section{REFLECTION}

The teaching practice indicates that by combining writing and speaking English and enhancing writing's facilitating function with speaking, it obviously improved the student's oral level as well as their writing level. The reasons are as follows: (1) The combination of oral and writing teaching together is in favor of the reconstruction of internalized knowledge. We know that if the material could be used to turn out utterances then it must have been understood, but one may not be able to turn out contents that he has understood. Only a part of the input material could become intake; and only one part of the intake material could be transformed to communication ability, and this transformation could only be realized when it reaches the point of automation. Writing helps to turn input into understanding and understanding into oral output. Therefore it is necessary to take writing as the supplement of oral teaching. (2) The combination of teaching and writing will promote the students to thinking in English. The process of writing is a process of thought enhancing. The improvement of any language needs a process, and the communication ability concerns elements of many aspects. During the process of speaking and writing the students constantly modify and correct their languages, which means they are reflecting on the language. While in the process of writing after class they will improve their language sense and induce the laws of language application. This is the metalanguage function in output, which helps the learners plan, supervise and evaluate their learning process and gradually cultivate the habit of thinking in English during conversations and writing processes. (3) the combination of oral teaching and writing helps to improve the coherence of language, which is in accordance with the Swain's hypothesis. When writing the students have bigger thinking space to mobilize all their innate knowledge and skills. They could fully use grammar, rhetoric, sentence pattern, transition and structure to express their thoughts. (4) When the frequency and quality of output are boosted, it will in turn promote the requirements of input frequency and quality, hence promote the ability of input, as is indicated by the experiment that the students' reading and listening levels are elevated. Then the comprehensive English level and its application ability will of course increase.

\section{SUGGESTIONS}

To employ this learning pattern, attention should be paid to the following aspects: (1)The teacher should be firm in his attitude. The success of this method mainly depends on after school study. Although many students subjectively applaud it, they are very lazy in carrying it out and frequently lose control of themselves. Therefore the teacher should exemplify to the students that he is not afraid of difficulties and is determined to go off. So they won't have the chance to quit.(2)The teacher should balance his power, giving enough to the students and retaining enough to supervise, get rid of obstacles in time and act as a guide. The responsibility and supervision of group leaders should be valued, and every member's participation should be ensured to have the activities carried out happily. (3) the task should be simple and easy to understand in order to ensure that the teacher's goal and plan are understand well.

\section{CONCLUSION}

In practical English teaching, the practice of enhancing output skill will promote the development of comprehensive language capability. This experience of writing will broaden the mind and release the learner's learning potential and speed up the transformation of language knowledge. The learner's application ability will be cultivated and thus boost their confidence of speaking and ability. This practice of combining writing and speaking effectively stimulates the existing and input information. The learner's comprehensive language capacity will be elevated. Therefore, it is feasible to apply this "double-output hypothesis" to task-based teaching approach.

\section{REFERENCES}

[1] Yang Chuan-pu. (1998). Speaking and Writing in Foreign Language Teaching. Foreign Languages and Foreign Language 
Teaching,(3).

[2] Yuan Hong-juan, etc. (2001). The Exploration of the Functions of Writing on Speaking in English Oral Teaching. Foreign Language Teaching,(6).

[3] Krashen, S. (1982).Principles and practice of second language acquisition. New York: Pergamon.

[4] Krashen. S. (1985). The Input Hypothesis: Issues and Implications. London: Longman Group Limited.

[5] Swain. M. (1995). Three Functions of Output in Second Language Learning: Principle and Practice in Applied Linguistics. London: Oxford University Press.

Yongmei Jiang was born in Qingdao, China in 1974. She received her M.A. degree in linguistics from The Ocean University of China in 2004.

She is currently a lecturer in the School of Foreign Languages, Qingdao University of Science and Technology, Qingdao, China. Her research interests include college English teaching and translation. 